TAPROBANICA, ISSN 1800-427X. June, 2014. Vol. 06, No. 01: pp. 21-26, 1 pl.

(C) Research Center for Climate Change, University of Indonesia, Depok, Indonesia \& Taprobanica Private Limited, Homagama, Sri Lanka http://www.sljol.info/index.php/tapro

\title{
USE OF TEA PLANTATION BY WILD MAMMALS IN TAMIL NADU, INDIA
}

\author{
Section Editor: Colin A. Chapman \\ Submitted: 21 January 2014, Accepted: 14 March 2014 \\ V. Gokula ${ }^{1,2}$ and C. Thangatamil ${ }^{1}$

\footnotetext{
${ }^{1}$ Post Graduate and Research Department of Zoology, National College, Tiruchirappalli 620001, Tamil Nadu, India

${ }^{2}$ E-mail: gokulae@yahoo.com
}

\begin{abstract}
Wild mammals that live in the fragmented primary forests in Western Ghats often leave the fragment due to resource shortages and use the nearby tea plantation either to forage or as a corridor to connect other fragments, during which time human-wildlife conflict is inevitable. Hence, understanding the need of wild mammals using the tea plantations is essential to minimize this conflict. We researched the use of tea plantations by wild mammals between October 2011 and January 2012 in Kolacamby, Nilgiris District, Tamil Nadu, India. Walks were made to determine the relative abundance of wild mammals inside the plantation. Scats of sloth bear (Melursus urisnus), tiger (Panthera tigiris), and leopard (Panthera pardus) found inside the plantation were analyzed to determine food habit. In addition, workers were informally interviewed about man-wildlife conflict. All major carnivores of the Western Ghats ecosystem were recorded in the area. Despite the richness of the fauna in the fragments, minimal human-wildlife conflict was reported.
\end{abstract}

Key words: habitat use, human-wildlife conflict, Kolacamby, mammals, tea plantation

\section{Introduction}

The Western Ghats in southern India have been recognized as a hotspot of biodiversity (Mayers et al., 2000); however, conversion of forests into agriculture land has already caused considerable loss of primary forests and landscapes (Menon \& Bawa, 1997). As a result, remaining primary forests are now found in a fragmented state (Kumar et al., 1995) either surrounded by human habitation or plantation. Wild animals that live in the primary forest often come out due to resource shortages or to move to other forest areas. In these circumstances, human-wildlife conflict is inevitable (Akhtar \& Chauhan, 2006; Bargali et al., 2005; Chauhan, 2003, 2004, 2005a,b; Mishra, 1997; Rajpurohit, 1996; Saberwal et al., 1994; Schultz, 1986; Singh, 2006; Vijayan \& Pati, 2001). Many conflicts are due to large, often endangered, animals such as elephant, tiger, sloth bear, leopard, while species of lesser conservation concern are also involved (e.g., nilgai, wild boar, jackal). 
In the Nilgiri Hill ranges, Kolakamby plateau is an example of a landscape where such conflict is common. On this plateau, several of land is cultivated primarily for tea by private and government owners. Large tracts of contiguous primary forests were cleared for such plantations during 1880s and still some forest patches exist under the management of the Forest Department of Tamil Nadu. Wild mammals from the nearby forest areas frequently use tea plantations. Since the plantation area has many human settlements human-wildlife animal is inevitable. Kumara et al. (2004) pioneered the study of wild animals in tea plantations in Valparai and we made a similar assessment to understand the use of tea plantations by wild mammals in Kolacamby, Nilgiris District, Tamil Nadu, India during October 2011 to January 2012.

\section{Materials and Methods}

Study area: A privately owned tea plantation, located between $76^{\circ} 44^{\prime} 54.24$ ' $\mathrm{E}$ and $11^{0} 17^{\prime} 9.6^{\prime} \mathrm{N}$ was selected near Kolacamby village, in Nilgiris District, Tamil Nadu (Fig. 1). The tea, Camellia sinensis (Theaceae), plantation is surrounded by primary forest on all the sides. The study area comes under Lousiana division (46.54 ha), Bhavani division (48.56 ha), and Muthanadu division (36.42 ha). Approximately 200 workers are currently working in the area. Both the sexes work in the factories, however, only women collect tea leaves. Leaf collection starts at $0800 \mathrm{~h}$ and ends at $1600 \mathrm{~h}$ with an hour break for lunch during $1200 \mathrm{~h}$ to $1300 \mathrm{~h}$ half an hour before the cease of both morning and evening session, collected leaves are weighed and loaded to the factory. Workers move in groups and work very closely in an organized manner while collecting leaves during work hours. Workers move separately only on their way home as their settlements are in different direction. Several perennial streams passed through the estate from adjacent forest areas. Dense vegetation is characterized by pioneer species; Mangifera indica (Anacardiaceae), Mallotus tetracoccus (Euphorbiaceae), Ficus hispida (Moraceae), Macaranga peltata (Euphorbiaceae), Persea macrantha (Lauraceae) and weeds; Lantana camara (Verbenaceae) and Eupatorium sp. (Asteraceae).

Data collection: To enumerate the wild animals using the tea plantation, the boundary path of the tea plantation was treated as transect and walked thrice in a month. Walks were made in the morning (between 0600 and $0900 \mathrm{~h}$ ), midday-1 (between $>0900 \mathrm{~h}$ and $1200 \mathrm{~h}$ ), midday-2 (between $>1200 \mathrm{~h}$ and $1600 \mathrm{~h}$ ), and in the evening (between 1600 and $1900 \mathrm{~h}$ ) from October 2011 to January 2012 in clear weather condition. All the wild mammals sighted, number of individuals sighted, sex (if possible), age (if possible), and activity were recorded. The data were used to determine the relative abundance of the different species. On many occasions, observations were made on several mammalian species for longer durations.

Scats of tiger, leopard, and sloth bear were also collected to identify the food habits. Scat collection and analysis of sloth bear followed methods used by Gokula et al. (1995), Baskaran et al. (1997), and Joshi et al. (1997). Scats were weighed. Samples were soaked in water for $10-15 \mathrm{~h}$, and then washed in running water to remove mud and other matter using 0.7 and $0.4 \mathrm{~mm}$ sieves. Scat samples were analyzed manually by separating components (such as ants, termites, and fruits) in the scats. A dissecting microscope was used to identify food items when needed. All inseparable, unidentifiable crushed matter, including parts of insects and fruits, was considered waste and discarded. Scat composition was quantified by both frequency of occurrence and percent dry weight of each food item. In addition to quantifying each item by species, we grouped into animal matter and plant matter.

Scats of the tigers and leopards are much larger and deposited on the grassy strips at the center and on sides of forest roads. On the other hand the group living dholes deposit their smaller scats in clusters on bare soil along the road wheel-track making them easily distinguishable from the two felids (Johnsingh, 1983; Karanth \& Sunquist, 1995). Tiger and leopard scats were separated using supplementary evidence such as difference in quantity, number of constrictions, distance between two constrictions and diameter of the scat and sometimes the presence of tracks (Karanth \& Sunquist, 1995). After identification a portion of the scat containing adequate amount of prey remains such as hair and other undigested body parts were collected. Scats were subsequently washed in a stream through a fine $(<1 \mathrm{~mm})$ nylon sieve (Cunningham et al., 1999). The 
sieved prey remains, grass and soil were sun dried in thin paper bags for three days to avoid fungal growth. The dried scat samples were then labeled and stored. Because hair passes undigested through the gut it was the primary source of information for identifying the prey species (Karanth \& Sunquist, 1995; Mukherjee et al., 1994a, b; Sunquist, 1981). The prey identification protocol was based on general appearance of the hair, color, relative length, relative width, texture, basal configuration, cortex pigmentation, medullary width and patterns as described by earlier workers (Karanth \& Sunquist, 1995; Putman, 1984; Sujai, 2004).

Additional information on human-animal conflict was gathered from the local people through personal interviews. All the two hundred workers were interviewed and their perceptions about wild animals were recorded. Workers who had sustained injuries in animalencounter inside the tea plantation were identified and a detail of the encounter was recorded.

\section{Results and Discussion}

All major carnivores of the Western Ghats ecosystem, including tiger, leopard, dhole, jackal, and smaller cats, such as jungle cat (Felis chaus), were recorded (Table 1).

Table 1: Number of encounters and relative abundance of large carnivores in the area $(n=93)$

\begin{tabular}{|lcc}
\hline \multicolumn{1}{c}{$\begin{array}{c}\text { Wild } \\
\text { mammal }\end{array}$} & $\begin{array}{c}\text { No. of } \\
\text { encounters }\end{array}$ & $\begin{array}{c}\text { Relative } \\
\text { abundance }\end{array}$ \\
\hline Tiger & 3 & 0.03 \\
\hline Leopard & 3 & 0.03 \\
\hline Jackal & 1 & 0.01 \\
\hline Smaller cat & 15 & 0.14 \\
\hline Gaur & 36 & 0.34 \\
\hline Mouse deer & 1 & 0.01 \\
\hline Barking deer & 3 & 0.03 \\
\hline Sloth Bear & 12 & 0.11 \\
\hline Wild boar & 9 & 0.09 \\
\hline Porcupine & 10 & 0.10 \\
\hline $\begin{array}{l}\text { Common } \\
\text { mongoose }\end{array}$ & 12 & 0.11 \\
\hline Total & $\mathbf{1 0 5}$ & $\mathbf{1 . 0 0}$ \\
\hline
\end{tabular}

Although pugmarks and scats of tigers were seen frequently in the adjacent forests, their presence was rare inside the estate. Only on three occasions, tiger and leopard were encountered. However, smaller cats were frequently sighted inside the estate. The relative abundance of smaller cats were high (0.16) compared to leopards (0.03) and tiger (0.03). Jackal (0.01) was sighted only once inside the plantation. Direct sightings of smaller cats were comparatively high, but they move very quickly and thus identification was not possible for many of the occasions. Among other large mammals; gaur, Bos gaurus was observed with the highest relative abundance $(0.34)$ followed by sloth bear, Melursus urisnus (0.11). Wild pig, Sus scrofa (0.09), mouse deer, Tragulus meminna (0.01), and porcupine, and Hystrix indica (0.10). Among small carnivores, common mongoose, Herpestes edwardsai was less common (0.11).

Dietary composition of the sloth bear has been studied based on frequency of occurrence and percent weight of different food items in scats (Gokula et al., 1995; Baskaran et al., 1997; Desai et al., 1997) as well as through direct observations of feeding behavior (Joshi et al., 1997). Sloth bears have morphological adaptations to feed on insects but, like other bear species, they are opportunistic omnivores and their diets varies seasonally and geographically (Joshi et al., 1997). As in other studies, sloth bears consumed both animal and plant matter, with variation probably related to food availability in different seasons (Laurie \& Seidensticker, 1977; Baskaran, 1990; Gokula et al., 1995; Baskaran et al., 1997; Joshi et al., 1997). In total, 50 scats of sloth bear were analyzed. Percent dry weight of food items found in the scats varied. Animal matters were more abundant during the months of November and December, while plant matters dominated the diet in October and January (Tables 2-4). Lantana camara, Ficus sp., Coffea arabica (Rubiaceae) were found in the scats of sloth bear and of which Lantana and Ficus sp. dominated most of the scats. Besides fruits, fibers (unidentified) were also often recorded in scats (Tables 2-4). In the animal matters, ants were very frequent, but the presence of honey bee was very meager (Table 5). We found that insects and fruits of Lantana camara and Ficus were the most frequently encountered food items in scats as reported by others (Baskaran, 
1990; Davidar, 1983; Gokula et al., 1995; Gopal, 1991; Joshi et al., 1997).

Table 2: Percent dry weight of plant and animal matter found in the scats of sloth bear.

\begin{tabular}{lcrr}
\hline Month & $\begin{array}{c}\text { No. of scats } \\
\text { analyzed }\end{array}$ & $\begin{array}{c}\text { Animal } \\
\text { matter }\end{array}$ & $\begin{array}{c}\text { Plant } \\
\text { matter }\end{array}$ \\
\hline Oct 2011 & 6 & $80 \%$ & $20 \%$ \\
Nov 2011 & 3 & $33.3 \%$ & $66.6 \%$ \\
\hline Dec 2011 & 5 & - & $100 \%$ \\
\hline Jan 2012 & 36 & $51.30 \%$ & $48.69 \%$ \\
\hline
\end{tabular}

Table 3: Percent dry weight of plant matter found in the scats of sloth bear.

\begin{tabular}{cclr}
\hline Month & $\begin{array}{c}\text { No. of } \\
\text { scats } \\
\text { analyzed }\end{array}$ & Plant species & \% \\
\hline Oct & 6 & Lantana camara & 100 \\
2011 & & Lantana camara & 50 \\
Nov & 3 & Fibers & 50 \\
2011 & & Fibers & 60 \\
Dec & 5 & Lantana camara & 20 \\
2011 & & Ficus sp. & 20 \\
& & Lantana camara & 83 \\
Jan & 36 & Coffea arabica & 4.5 \\
2012 & & Rubus sp. & 1.5 \\
& & Fibers & 11 \\
\hline
\end{tabular}

Table 4: Percent dry weight of animal matter found in the scats of Sloth Bear

\begin{tabular}{cclr}
\hline Month & $\begin{array}{c}\text { No. of } \\
\text { scats } \\
\text { analyzed }\end{array}$ & Animal species & \% \\
\hline Oct & 6 & Ants & 91.6 \\
2011 & & Ant's Pupae & 8.4 \\
\hline Nov & 3 & Ants & 100 \\
2011 & & & \\
Dec & 5 & - & - \\
2011 & & Ants & 95.5 \\
Jan & 36 & Honey bee & 4.5 \\
2012 & & & \\
\hline
\end{tabular}

Sambar (Cervus unicolor) is a major prey species for leopards and tigers in mature forests (Fox \& Johnsingh 1975) and the same may be true in the present study as hairs of sambar were predominantly found in the scats of leopard and tiger although the sample size was very low (Table 5). No species of wild animal was found spending the whole day inside the plantation however, animals were frequently observed during the early morning and late evening hours (Fig. 2). No animals were found in the tea plantation during the hottest hours of the day. The presence of open grass patches between the tea plantation and the nearby streams provides a very good foraging opportunity to the herbivore animals. On the other hand, presence of fruits of Lantana sp., Ficus sp., and Rubus sp. in and around the plantation attract the sloth bear. A forest usually has a good crown cover. Because of the low penetration of light through such a canopy, the forests do not offer much grass for grazers. On the other hand, a tea plantation is almost totally open, with largely spaced oak trees. Because of the high elevation, medium temperature, and high rainfall, effusive grass grows in all open spaces, including roadsides. This provides excellent grazing grounds and attracts grazers from the nearby forests. Large herbivores such as gaurs were observed to visit the estate grasslands only after dusk and they always returned to the forests before sunrise. Small mammals, such as porcupine and mongooses, were probably residents in the estate, using rocks and tree holes near stream vegetation as shelters.

Table 5: Percent dry weight of prey matters found in the scats of tiger and leopard

\begin{tabular}{|c|c|c|c|}
\hline Month & $\begin{array}{c}\text { No of scats } \\
\text { analyzed }\end{array}$ & $\begin{array}{c}\text { Animal } \\
\text { matter }\end{array}$ & $\begin{array}{l}\text { Plant } \\
\text { matter }\end{array}$ \\
\hline \multicolumn{4}{|l|}{ Tiger } \\
\hline $\begin{array}{c}\text { Oct } \\
2011\end{array}$ & - & - & - \\
\hline $\begin{array}{l}\text { Nov } \\
2011\end{array}$ & 1 & $\begin{array}{l}\text { Sambar } \\
(100 \%)\end{array}$ & - \\
\hline $\begin{array}{c}\text { Dec } \\
2011\end{array}$ & & - & - \\
\hline $\begin{array}{c}\text { Jan } \\
2012\end{array}$ & 1 & $\begin{array}{l}\text { Sambar } \\
(100 \%)\end{array}$ & - \\
\hline \multicolumn{4}{|c|}{ Leopard } \\
\hline $\begin{array}{c}\text { Oct } \\
2011\end{array}$ & 1 & $\begin{array}{l}\text { Sambar } \\
(100 \%)\end{array}$ & - \\
\hline $\begin{array}{l}\text { Nov } \\
2011\end{array}$ & 2 & $\begin{array}{l}\text { Sambar } \\
(100 \%)\end{array}$ & - \\
\hline $\begin{array}{c}\text { Dec } \\
2011\end{array}$ & 1 & $\begin{array}{l}\text { Black-napped } \\
\text { hare }(14 \%) \\
\text { Sambar }(86 \%)\end{array}$ & - \\
\hline $\begin{array}{c}\text { Jan } \\
2012\end{array}$ & 1 & $\begin{array}{l}\text { Wildboar } \\
(86 \%)\end{array}$ & $\begin{array}{l}\text { Grass } \\
(14 \%)\end{array}$ \\
\hline
\end{tabular}

Among the wild animals, no reports of tigers and leopard attacking workers were evident however, six workers were mauled by sloth bear during the last ten years. As animals were largely seen inside the plantation during the early morning and late evening hours of a day, workers had a very limited opportunity to encounter with wild animal. All the six cases happened in the early hours when workers went alone for some other purposes outside the 
plantation. Most of the time while working, workers move in groups and work very nearby and thus rate of encounter with animals is infrequent. These observations indicate that the human-animal conflict was minimal inside the plantation. The only negative impact of wild mammals for planters was the damage done to the root systems of plants because of digging by sloth bears, wild pigs, and porcupines.

The tea plantations of Kolacamby were used effectively by as many as 11 species of wild mammals either as foraging grounds or as a corridor to connect other natural forest. Wild mammals frequented the tea plantations largely during the early morning and late evening. Although minimal, man-bear conflict was found outside the tea plantations.

\section{Acknowledgements}

We are grateful to the management of Muthunadu, Bhavani and Luciana Tea plantations, at Kolacamby for permitting us to collect the needed information and to the workers of the plantation who generously shared their experience particularly about their encounter with wild animals with the second author during his stay.

\section{Literature cited}

Akhtar, N. and N. P. S. Chauhan, 2006. Humansloth bear conflict and mitigation strategies in Chhattisgarh, India. Bear News, 21: 4.

Bargali H. S., N. Akhtar, and N. P. S. Chauhan, 2005. Characteristics of sloth bear attacks in North Bilaspur forest division. Ursus, 16 (2): 263-267.

Baskaran, N., 1990. An ecological investigation on the dietary composition and habitat utilization of sloth bear (Melursus ursinus) at Mudumalai wildlife sanctuary, Tamil Nadu (South India). MSc Thesis, A.V.C. College, Mannampandal, Tamil Nadu, India: 128.

Baskaran, N., N. Sivaganesan, and J. Krishnamoorthy, 1997. Food habits of the sloth bear in Mudumalai Wildlife Sanctuary, Tamil Nadu, Southern India. Journal of Bombay Natural History Society, 94 (1): 1-9.

Chauhan, N. P. S., 2003. Human casualties and livestock depredation by black and brown bear in the Indian Himalaya. Ursus, 14 (1): 84-87.
Chauhan, N. P. S., 2004. Crop depredation by Himalayan black bear and mitigation strategies in the Great Himalayan National Park, Himachal Pradesh, India. $15^{\text {th }}$ International Conference on Bear Research and Management, San Diego, California. February 8-13, 2004.

Chauhan, N. P. S., 2005a. Human casualties by tiger in Katerniaghat Wildlife sanctuary Uttar Pradesh and mitigation strategies. Indian Forester, 131 (10): 1347-1352.

Chauhan, N. P. S., 2005b. Livestock depredation by tiger in and around Dudhwa National Park, Uttar Pradesh and mitigation strategies. Indian Forester, 131 (10): 1319-1328.

Cohen, J. A., M. W. Fox, A. J. T. Johnsingh, and B. D. Barnett, 1975. Food habits of the dhole in South India. Journal of Wildlife Management, 42: 933-936.

Cunningham, S. C., C. Gustavson, and W. B. Ballard, 1999. Diet selection of mountain lions in southeastern Arizona. Journal of Range Management, 53: 202-207.

Desai, A. A., N. Baskaran, and S. Venkatesh, 1997. Behavioural ecology of the sloth bear in Mudumalai Wildlife Sanctuary and National Park, Tamil Nadu. Report. Bombay Natural History Society, Bombay, India, and Tamil Nadu Forest Department, Chennai, India.

Gokula, V., N. Sivaganesan, and M. Varadharajan, 1995. Food of the sloth bear (Melursus ursinus) in Mundanthurai Plateau, Tamil Nadu. Journal of Bombay Natural History Society, 92: 408-410.

Johnsingh, A. J. T., 1983. Large mammalian prey-predator in Bandipur. Journal of Bombay Natural History Society, 80: 1-57.

Joshi, A. R., D. L. Garshelis, and L. D. Smith, 1997. Seasonal and habitat-related diets of sloth bears in Nepal. Journal of Mammalogy, 78: 584597.

Karanth, K. U. and M. E. Sunquist, 1995. Prey selection by tiger, leopard and dhole in tropical forests. Journal of Animal Ecology, 64: 439-450.

Kumar, A., G. Umapathy, and A. Prabhakar, 1995. A study on the management and conservation of small mammals in fragmented rainforests in the Western Ghats, South India: A 
preliminary report. Primate Conservation, 16: $53-58$.

Kumara, H. N, Ananda Kumar, A. K. Sharma, H. S. Sushma, Mridula Singh, and Mewa Singh, 2004. Diversity and management of wild mammals in tea gardens in the rain-forest regions of the Western Ghats, India: A case study from a tea estate in the Anaimalai Hills. Current Science, 87 (9): $1282-1287$

Landers, J. L., R. J. Hamilton, A. S. Johnson, and R. L. Marchinton, 1979. Food habits of black bears in Southern North Carolina. Journal of Wildlife Management, 43: 143-153.

Lauries, A. and J. Seidensticker, 1977. Behavioural ecology of the sloth bears (Melursus ursinus). Journal of Zoology (London), 182: 187204.

Maehr, D. S. and J. R. Brady, 1984. Food habits of Florida black bears. Journal of Wildlife Management, 48: 230-235.

Menon, S. and K. S. Bawa, 1997. Application of geographic information systems, remote-sensing, and a landscape ecology approach to biodiversity conservation in the Western Ghats. Current Science, 73:134-144.

Mishra, C., 1997. Livestock depredation by large carnivore in the Indian trans-Himalaya: conflict perception and conservation prospects. Environmental conservation, 24 (4): 338-343.

Mukherjee, S., S. P. Goyal, and R. Chellam, 1994a. Refined techniques for the analysis of Asiatic Lion Panthera leo persica scats. Acta Theriologica, 39: 425-430.

Mukherjee, S., S. P. Goyal, and R. Chellam, 1994b. Standardisation of scat analysis techniques for leopard (Panthera pardus) in Gir National Park, Western India. Mammalia, 58: 139-143.

Myers, N., R. A. Mittermeier, C. G. Mittermeier, G. A. B. La Fonseca, and J. Kent, 2000. Biodiversity hotspots for conservation priorities. Nature, 403, 853-858.

Putman, R. J., 1984. Facts from faeces. Mammal Review, 14: 79-97.

Rajpurohit, K. S., 1996. Study of wild animal damage problems in and around protected areas and managed forests in India. Phase-1, Madhya
Pradesh, Bihar and Orissa. WII report, Wildlife Institute of India, Dehradun, India.

Schaller, G. B., 1967. The deer and the tiger: a study of wildlife in India. University of Chicago Press, Chicago, USA: 366.

Saberwal, V. K., J. P. Gibbs, R. Chellam, and A. J. T. Johnsingh, 1994. Lion-human conflict in Gir forest, India. Conservation Biology, 8 (2): 501507.

Sunquist, M. E., K. U. Karanth, and F. Sunquist, 1999. Ecology, behaviour and resilience of the tiger and its conservation needs. In: Seidensticker, J., S. Christie, and P. Jackson (Eds.). Riding the tiger: tiger conservation in human dominated landscapes. Cambridge University Press, UK: 518.

Schultz, B. O., 1986. The management of crop damage by wild animals. Indian Forester, 112 (10): 891-899.

Singh, H. S., 2006. Growing man-leopard conflicts in Gujarat State, India. Indian Forester, $1243-1253$.

Sujai, R., 2004. Diet profile of three large sympatric carnivores in Central India. MSc. Thesis. Bharathidasan University, Tamil Nadu, India.

Sunquist, M. E., 1981. The social organisation of tigers (Panthera tigris) in Royal Chitwan National Park. Smithson. Contributions to Zoology, 336: 1-98.

Vijayan, S and B. P. Pati, 2001. Impact of changing cropping patterns on man-animal conflicts around Gir Protected Area with specific reference to Talala subdistrict, Gujarat, India. Population and Environment, 23: 541-559. 


\section{PLATE 8}

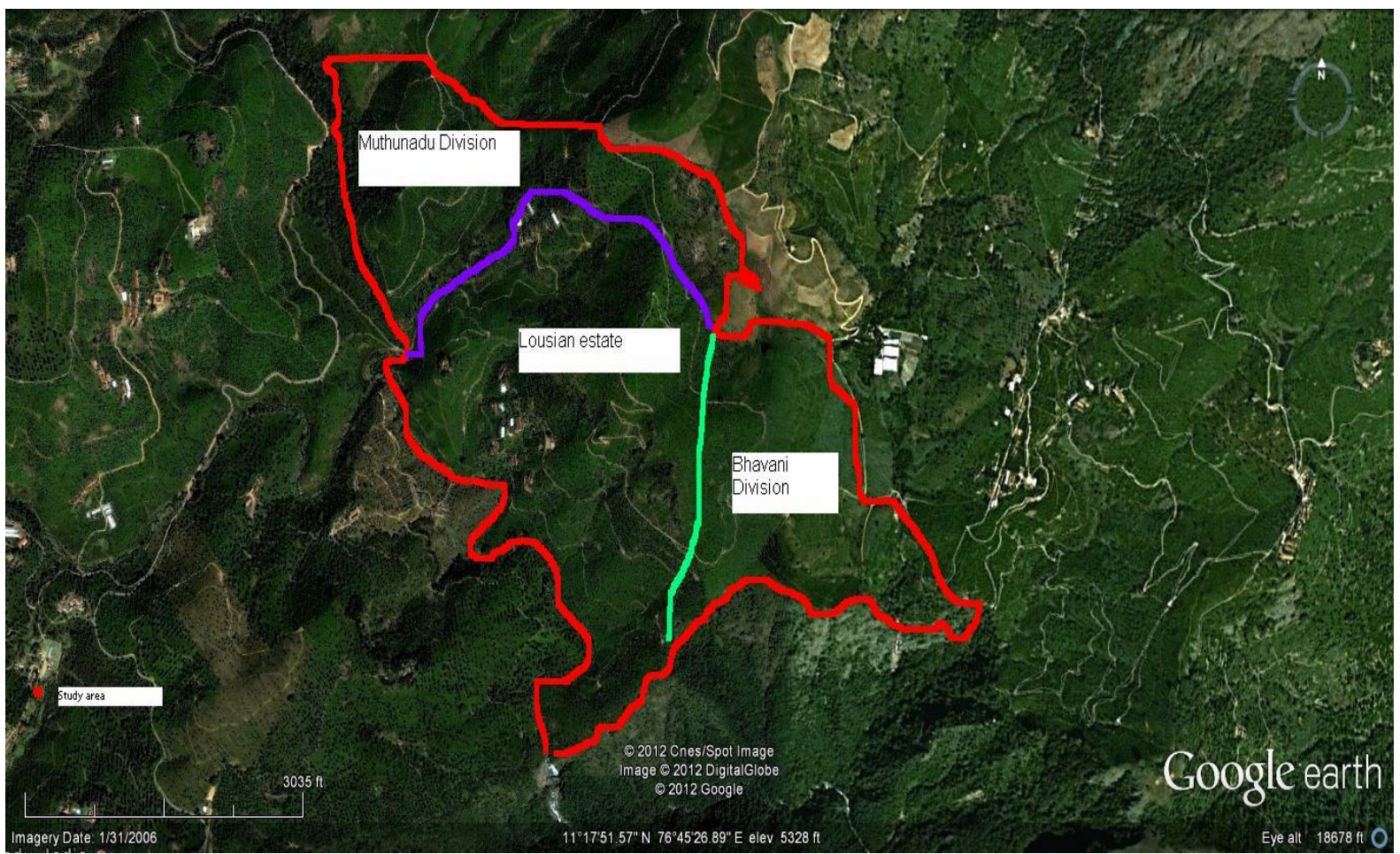

Figure 1: A map of the study area.

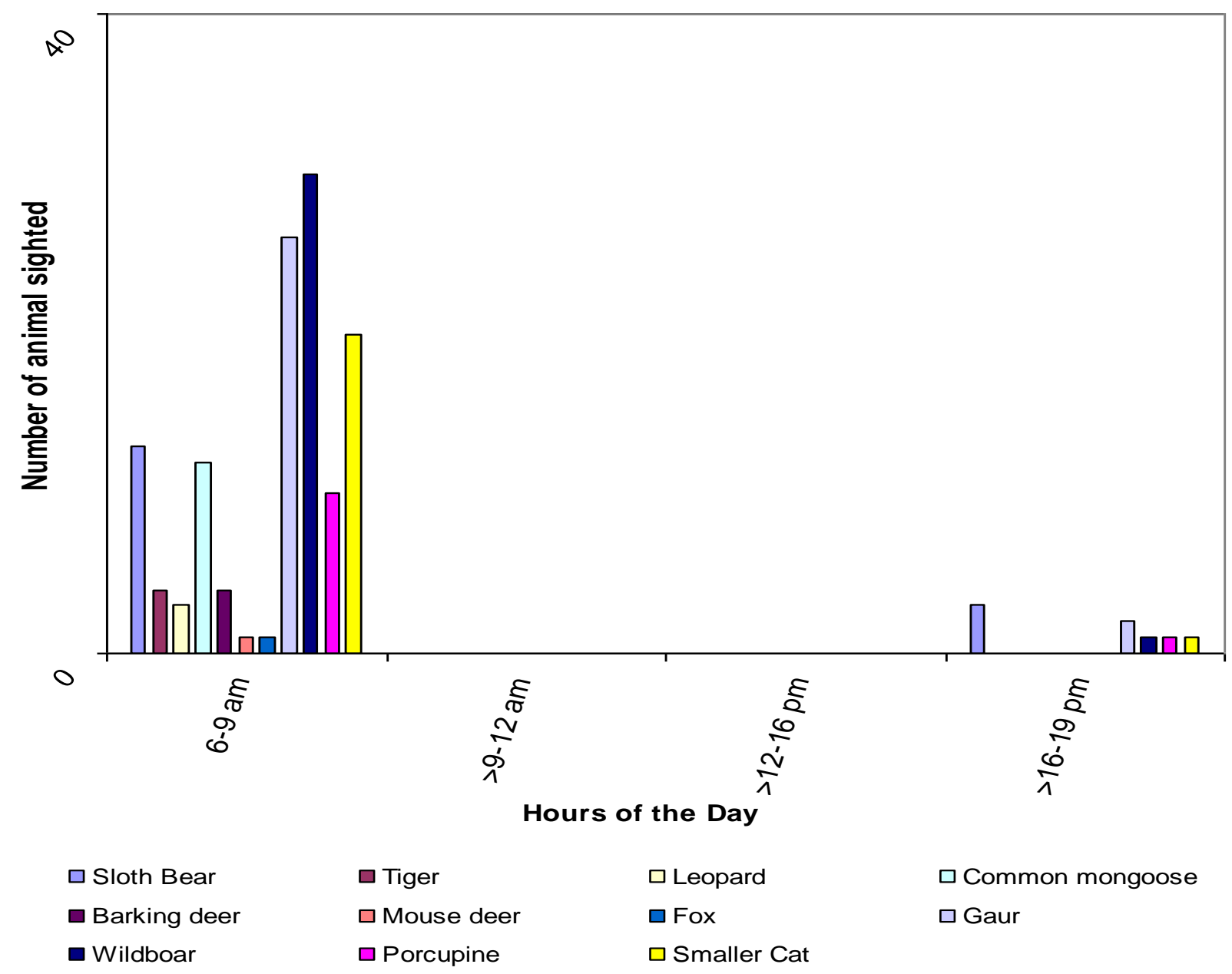

Figure 2: Sightings of wild mammals in the tea plantation during the study (number of herds is represented for gaur) 